\title{
Effects of ozone stimulation of bronchial epithelial cells on proliferation and collagen synthesis of co-cultured lung fibroblasts
}

\author{
YUE WANG $^{1,2}$, MEILING TAN ${ }^{3}$, HAIPING OUYANG $^{4}$ and LINHONG DENG ${ }^{1,2}$ \\ ${ }^{1}$ Changzhou Key Laboratory of Respiratory Medical Engineering, Institute of Biomedical Engineering and Health Sciences; \\ ${ }^{2}$ Department of Nursing, School of Pharmaceutical Engineering and Life Science, Changzhou University, Changzhou, \\ Jiangsu 213164; ${ }^{3}$ Department of Physiology, School of Basic Medicine, Central South University, Changsha, \\ Hunan 410078; ${ }^{4}$ State Key Laboratory of Respiratory Diseases, Guangzhou Institute of Respiratory Disease, \\ The First Affiliated Hospital of Guangzhou Medical University, Guangzhou, Guangdong 510000, P.R. China
}

Received July 16, 2017; Accepted March 1, 2018

DOI: $10.3892 /$ etm.2018.6122

\begin{abstract}
Ozone $\left(\mathrm{O}_{3}\right)$ as a major air pollutant is widely recognized for causing pathological changes of the airway system. However, it is not clear whether $\mathrm{O}_{3}$ exposure of bronchial epithelial cells (BECs) influences the proliferation and collagen synthesis of submucosal fibroblasts and contributes to the pathogenesis of airway remodeling in diseases, including asthma. In the present study, a co-culture method was applied to culture human lung fibroblasts (HLFs) with human bronchial epithelial cells (HBECs) that were pre-stimulated with $\mathrm{O}_{3}$. Following co-culture for up to $24 \mathrm{~h}$, the proliferation of HLFs was measured using MTT colorimetry. Furthermore, the collagen synthesis capacity of HLFs was determined by the level of hydroxyproline. In addition, the protein expression levels of cytokines, including transforming growth factor (TGF)- $\beta 1$, tumor necrosis factor (TNF)- $\alpha$ and prostaglandin E2 (PGE2) were assessed. Results indicated that the proliferation of HLFs co-cultured with HBECs was significantly inhibited when compared with HLFs cultured alone $(\mathrm{P}<0.05)$. By contrast, co-culture with $\mathrm{O}_{3}$-stimulated HBECs significantly promoted the proliferation of HLFs compared with the HLFs cultured alone or those cultured with HBECs but no $\mathrm{O}_{3}$ stimulation, respectively $(\mathrm{P}<0.05$ and $\mathrm{P}<0.01)$. Furthermore, similar effects were observed regarding the collagen synthesis capacity of HLFs co-cultured with HBECs for 24 . In the supernatant, TGF- $\beta 1$ concentration was continuously increased over $24 \mathrm{~h}$, whereas the concentration of PGE2 increased and plateaued between 12 to $24 \mathrm{~h}$ and TNF- $\alpha$ concentration was not significantly altered during the assessed time period. To conclude, the present results suggest that $\mathrm{O}_{3}$ pre-exposure of HBECs may promote the transformation of
\end{abstract}

Correspondence to: Dr Linhong Deng, Changzhou Key Laboratory of Respiratory Medical Engineering, Institute of Biomedical Engineering and Health Sciences, Changzhou University, 1 Gehu Road, Changzhou, Jiangsu 213164, P.R. China

E-mail:dlh@cczu.edu.cn

Key words: bronchial epithelial cells, lung fibroblast, ozone, proliferation, collagen synthesis, cytokine secretion
HLFs from the typical inhibitory state into a promoting state with respect to proliferation and collagen synthesis, which may likely occur through a mechanism that influences the balance between pro- and anti-inflammatory factors, including TGF- $\beta 1$ and PGE2. The present findings may improve the understanding of the mechanism involved in $\mathrm{O}_{3}$-induced airway remodeling from a novel perspective of maintenance/loss of steady-state function of the airway epithelium.

\section{Introduction}

Bronchial asthma is a chronic airway inflammatory disease mediated by a variety of cell types and factors (1). A key hallmark associated with bronchial asthma is marked airway remodeling, which at tissue and cellular levels primarily includes airway wall thickening, airway epithelial fibrosis, airway smooth muscle cell hyperplasia and hypertrophy and myofibroblast proliferation and activation (2). At a molecular level, the pathological changes of airway remodeling are known to be associated with increased deposition of extracellular matrix (ECM) components, including type I, III and IV collagen fibers and fibronectin (3-5). Although the underlying mechanism of airway remodeling is not fully understood, it is generally acknowledged that airway remodeling is predominantly a result of the imbalance of airway injury and repair following repeated airway injury from chronic exposure to hazardous environmental factors and abnormal repair due to chronic airway inflammation (2). This association between airway remodeling and environmental hazards may be a contributing factor to the rising incidence of bronchial asthma, particularly in industrial countries worldwide during recent decades; the highest prevalence of clinical asthma worldwide were reported in Australia, Sweden, UK, Netherlands and Brazil were 21.5, 20.2, 18.2, 15.3 and $13.0 \%$, respectively (6).

Among the environmental hazardous factors known to cause adverse effects on health, ozone $\left(\mathrm{O}_{3}\right)$ is a major factor in air pollution, which is widely recognized as a particularly harmful risk to airway health $(7,8)$. In human and animal studies, it has been demonstrated that early exposure at post-natal stage or long-term exposure at later stages to $\mathrm{O}_{3}$ may result in pathological changes in the respiratory system, including modifications of time and mode of alveolar growth 
and development $(9,10)$. It has been reported that $\mathrm{O}_{3}$ exposure may also cause inflammation in the airways and the lungs and structural reorganization of smooth muscle cells $(11,12)$. Previous studies indicated that $\mathrm{O}_{3}$ induced oxidative stress to airway epithelial cells cultured in vitro, resulting in the release of nitric oxide and epithelial cell injury (13), and that exposure to $\mathrm{O}_{3}$ of the bronchial epithelium resulted in airway inflammation and airway hyperresponsiveness $(14,15)$.

Notably, there is little evidence to support whether $\mathrm{O}_{3}$ exposure may result in airway remodeling. The limited reports regarding this may partly be due to the fact that $\mathrm{O}_{3}$ directly targets bronchial epithelial cells (BECs) but not the fibroblasts that reside beneath these cells, which serve a key role in airway remodeling (16).

In order to explore the association between $\mathrm{O}_{3}$ exposure and airway remodeling, it was hypothesized that BECs exposed to $\mathrm{O}_{3}$ will release inflammatory growth factors, including transforming growth factor (TGF)- $\beta 1$, which may subsequently enhance the secretion and activity of collagen from adjacent fibroblasts in the airway wall and ultimately result in airway remodeling. To investigate this hypothesis in the present study, a co-culture model of human lung fibroblasts (HLFs) and human bronchial epithelial cells (HBECs) was constructed. $\mathrm{O}_{3}$ stress was applied to the HBECs and cell proliferation and secretion of cytokines in the HLFs were assessed. The present study aimed to elucidate the mechanism of $\mathrm{O}_{3}$-induced airway remodeling from a novel perspective of maintenance/loss of steady-state function of the airway epithelium.

\section{Materials and methods}

HBE and HLF culture. HBECs from a cell line were provided by Professor Gruenent of University of California, San Francisco (San Francisco, USA) (17). Embryonic diploid HLF-02 HLFs were purchased from the Cell Center of Central South University (Changsha, China). HBECs were seeded in Dulbecco's modified Eagle medium (DMEM)/F12 (1:1 ratio; Hyclone, Logan, UT, USA) supplemented with $15 \%$ newborn calf serum (Gibco; Thermo Fisher Scientific, Inc., Waltham, MA, USA), 100 U/ml penicillin and $100 \mathrm{U} / \mathrm{ml}$ streptomycin in a $100-\mathrm{ml}$ culture flask. Cells grew adherently at $37^{\circ} \mathrm{C}$ until $80 \%$ confluence was reached. Subsequently, the culture medium was displaced and the cells were rinsed with phosphate-buffered saline one to two times. Following this, HBECs were trypsinized with $1 \mathrm{ml}$ $0.25 \%$ trypsin with $0.05 \%$ EDTA and scattered gently through a pipette to create the cell suspension. HBECs were divided in 1:2 or $1: 3$ proportions for subculture. When cells in subculture grew to $80 \%$ confluence with a healthy, cuboid morphology, they were seeded on culture plates for subsequent experiments. HLFs were cultured and prepared for experiments as described above.

Co-culture of HLFs and $\mathrm{O}_{3}$-stimulated HBECs. Prior to co-culture, confluent HBECs in subculture flasks were harvested by trypsinization and then counted manually using trypan blue $(0.4 \%)$ staining to detect the live cells. HBECs were seeded onto coverslips that had been placed in 24-well culture plates (Thermo Fisher Scientific, Inc.) at $1 \times 10^{5}$ cells $/ \mathrm{ml}(1 \mathrm{ml}$ per well). Subsequently, the cells were cultured at $37^{\circ} \mathrm{C}$ and $5 \% \mathrm{CO}_{2}$ for $48 \mathrm{~h}$ in DMEM medium supplemented with $15 \%$ newborn calf serum to allow the cells to adhere to the coverslip. After
$48 \mathrm{~h}$, the medium was replaced with DMEM supplemented with $1 \%$ newborn calf serum (Gibco; Thermo Fisher Scientific, Inc.).

To establish the $\mathrm{O}_{3}$ stimulated HBECs group, HBECs were prepared as above and were incubated in DMEM supplemented with $1 \%$ newborn calf serum for $8 \mathrm{~h}$. Subsequently, HBECs were stimulated with $\mathrm{O}_{3}(2 \mathrm{ppm})$ for $30 \mathrm{~min}$ and incubated for $1 \mathrm{~h}$ prior to co-culture with HLFs. For the control (HBECs) group, the HBECs followed the same time course and procedure, with the exception that the HBECs were not exposed to $\mathrm{O}_{3}$ for $30 \mathrm{~min}$.

HLFs were also harvested and counted as described above for HBECs. HLFs were seeded into the 24-well plates at $2 \times 10^{4}$ cells $/ \mathrm{ml}$ ( $1 \mathrm{ml}$ per well). HLFs were cultured in DMEM supplemented with $15 \%$ newborn calf serum for $12 \mathrm{~h}$ to allow the cells to adhere to the culture dish. The medium was replaced with DMEM supplemented with $1 \%$ newborn calf serum and cells were incubated for a further $12 \mathrm{~h}$. Subsequently, a sterile stainless steel screen mesh was inserted into each well containing the HLFs and a coverslip with HBECs that had been stimulated or not simulated with $\mathrm{O}_{3}$ was placed on top of the stainless steel screen mesh that provided separation between the HBECs and HLFs in the same well. HBECs and HLFs were co-cultured in the same well for $24 \mathrm{~h}$. following this, the coverslip and the mesh were removed from the well, respectively, and the proliferation of HLFs was assessed by MTT colorimetric method.

MTT colorimetry for evaluation of cell proliferation. The proliferation of HLFs was evaluated using the MTT colorimetric method. HLFs were divided into the following three groups: Fibro group, which contained HLFs that had been cultured alone; co-culture group, which contained HLFs co-cultured with $\mathrm{HBECs}$ without $\mathrm{O}_{3}$ stimulation; and $\mathrm{O}_{3}$ co-culture group, which contained HLFs co-cultured with $\mathrm{O}_{3}$-stimulated HBECs. Cells were seeded at $2 \times 10^{4}$ cells $/ \mathrm{ml}(1 \mathrm{ml} / \mathrm{well})$ in 24-well plates and treated with $100 \mu \mathrm{l}$ of $0.5 \%$ MTT solution. Cells were incubated at $37^{\circ} \mathrm{C}$ for $4 \mathrm{~h}$ and the supernatant was removed. A total of $800 \mu$ dimethyl sulfoxide was added to each well followed by 10 min steady oscillation of the 24 -well plates. The cell suspension was aliquoted into 96-well plates and was analyzed using an automatic microplate reader (Elx800, Thermo Fisher Scientific, Inc., Waltham, MA, USA) at $570 \mathrm{~nm}$. Culture medium without cells served as a blank control. Each experiment was repeated six times.

The proliferation of HBECs in the $\mathrm{O}_{3}$ stimulated and control groups was assessed as described above. The proliferation of HBECs was measured at 1, 12 and $24 \mathrm{~h}$. Each measurement was repeated four times.

Assessment of HLF collagen synthesis. Collagen synthesis in HLFs was determined by assessing the hydroxyproline levels in HLF culture medium supernatant using a hydroxyproline kit (cat. no. A030-1; Nanjing Jiancheng Bioengineering Institute, Nanjing, China) according to the manufacturer's instructions. Hydroxy proline is a major component of collagen (18). Therefore, measurement of hydroxyproline levels in cell culture medium indicates the ability of the cell to produce collagen (18-21). To Pleameasure the hydroxyproline levels in the culture medium supernatant, $0.5 \mathrm{ml}$ of culture medium was combined with $1 \mathrm{ml}$ hydrolysate and hydrolyzed for $20 \mathrm{~min}$ in a boiling water bath (pH 6.0-6.8). A blank tube with distilled water, a standard tube with $5 \mu \mathrm{g} / \mathrm{ml}$ standard solution and a measurement tube with 

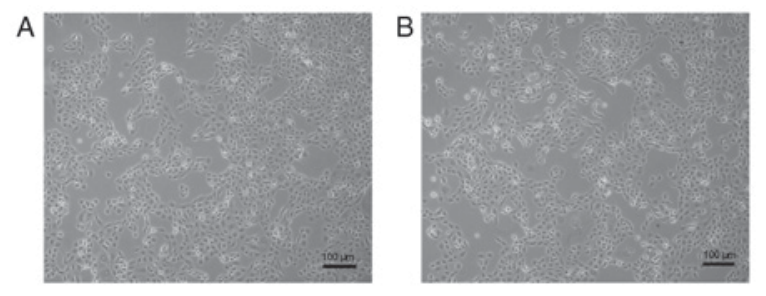

\section{$\mathrm{O}_{3}$ dosage:}

$2 \mathrm{ppm}, 30 \mathrm{~min}$

each treatment
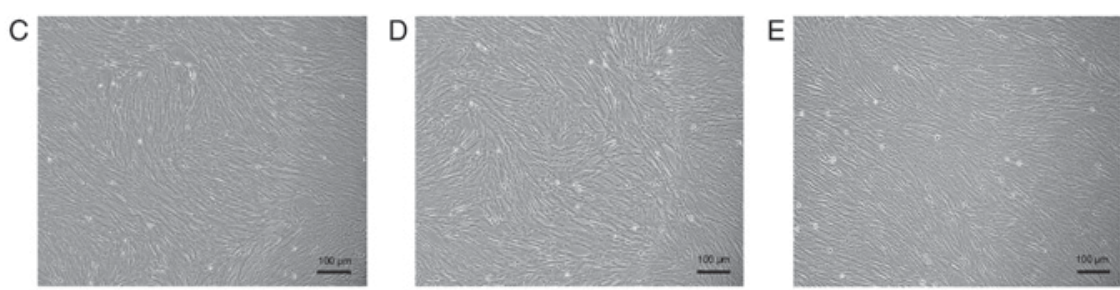

Figure 1. Representative microscopic images of HBECs and HLFs cultured alone or co-cultured with or without $\mathrm{O}_{3}$ stimulation. (A) HBECs cultured alone without $\mathrm{O}_{3}$ stimulation, (B) HBECs cultured alone with $\mathrm{O}_{3}$ stimulation, (C) HLFs cultured alone, (D) HLFs co-cultured with $\mathrm{HBECs}$ without $\mathrm{O}_{3}$ stimulation and (E) HLFs co-cultured with $\mathrm{O}_{3}$-stimulated HBECs (magnification, $\mathrm{x} 50$ ). $\mathrm{O}_{3}$ stimulation was given at a dosage of 2 ppm, 30 min for each treatment. Scale bar=100 $\mu \mathrm{m}$. HBECs, human bronchial epithelial cells; HLFs, human lung fibroblasts; $\mathrm{O}_{3}$, ozone.

the hydrolyzed supernatant of culture medium were prepared, respectively. Subsequently, a 1-ml sample was taken from each tube and mixed with reagent One. Following 10 min standing at room temperature, each sample was mixed with reagent Two and left to stand for $5 \mathrm{~min}$ at room temperature. Following this, the sample was mixed with reagent Three, incubated at $60^{\circ} \mathrm{C}$ for $15 \mathrm{~min}$, cooled and centrifuged at $4^{\circ} \mathrm{C}, 2,054 \mathrm{x}$ g for $10 \mathrm{~min}$. The absorbance of the supernatant was measured at $550 \mathrm{~nm}$. Each tube was repeatedly measured four times. Total protein was assayed using the Lowry protein assay (22). Hydroxyproline levels were calculated as follows: Hydroxyproline $(\mu \mathrm{g} / \mathrm{mg}$ protein $)=[$ optical density $(\mathrm{OD})$ of test tube/OD of standard sample tube]x(concentration of standard sample/total protein).

Detection of TGF- $\beta 1, T N F-\alpha$ and PGE2 concentration in the supernatant of the co-cultured system and HBECs cultured alone. The concentration of inflammatory mediators TGF- $\beta 1$ and TNF- $\alpha$ in the supernatant of $\mathrm{O}_{3}$-stimulated HBECs co-cultured with HLFs was assessed at 6, 12, 18 and $24 \mathrm{~h}$ following co-culture using ELISA kits (cat. no. MM-0090H1 and MM-0122H1, respectively; Jingmei Bioengineering Co., Ltd., Yancheng, China) according to the manufacturer's protocol. The OD value measured at $450 \mathrm{~nm}$ was directly proportional to the concentration of the indicator. By constructing a standard curve, the concentration of TGF- $\beta 1$ and TNF- $\alpha$ in the specimen could be determined accordingly. The concentration of the inflammatory mediator PGE2 in the supernatant of the co-cultured system was measured using a PGE2 radioimmunoassay kit (cat. no. ADI-905-025-1; Enzo Life Sciences, Inc., Farmingdale, NY, USA) according to the manufacturer's protocol. The concentration of PGE2 in the sample was directly calculated using an automatic $\gamma$ immuno-counter. The TGF- $\beta 1$, TNF- $\alpha$ and PGE2 concentration was detected in the supernatant of $\mathrm{O}_{3}$-stimulated HBECs and HBECs cultured alone at $24 \mathrm{~h}$ as described above.

Detection of TGF- $\beta 1$ protein expression levels in HBECs alone or co-cultured with HLFs. The protein expression levels of TGF- $\beta 1$ in HBECs alone or co-cultured with HLFs were detected using an immunocytochemistry method. Cells were labeled for
TGF- $\beta 1$ expression using an immunocytochemistry staining kit (cat. no. SA1022; Wuhan Boster Biological Technology Ltd., Wuhan, China) according to the manufacturer's instructions. Cells were fixed with $95 \%$ alcohol at room temperature for 15 min and dipped in $30 \% \mathrm{H}_{2} \mathrm{O}_{2}$ combined with $100 \%$ methanol (1:50 ratio) at room temperature for $30 \mathrm{~min}$ to block endogenous peroxidase activity. Cells were immersed in 5\% bovine serum albumin blocking reagent at room temperature for $20 \mathrm{~min}$. Following this, cells were treated with TGF- $\beta 1$ antibodies $\left(1: 1,000\right.$; cat. no. BA0290) at $37^{\circ} \mathrm{C}$ for $1-2 \mathrm{~h}$ and biotinylated goat anti-rabbit IgG antibodies (1:500; cat. no. BA1003; both Wuhan Boster Biological Technology Ltd.) at room temperature for 20 min. Reagent SABC (Wuhan Boster Biological Technology Ltd.) was added at room temperature for $20 \mathrm{~min}$. Cells were subsequently counterstained with hematoxylin at room temperature for $30 \mathrm{sec}$, dehydrated and observed under an optic microscope. For quantification of TGF- $\beta 1$ expression in HBECs, images were captured of five randomly selected fields of view and analyzed using a medical image analysis and management system (MIAS version 4.1; Image Processing Center of Beihang University, Beijing, China) to assess the photodensity.

Statistical analysis. Data was presented as the mean \pm standard deviation from the representative experiment. Each experiment was repeated four to six times. All data were processed using SPSS 21.0 software (IBM Corp., Armonk, NY, USA). An unpaired Student's t-test was performed to determine the statistical difference between two groups and multiple comparisons were determined using one-way analysis of variance followed by Dunnett's t-test. Correlations were analyzed using Pearson's correlation analysis method. $\mathrm{P}<0.05$ was considered to indicate a statistically significant difference.

\section{Results}

Effect of $\mathrm{O}_{3}$ stimulation on cell morphology and proliferation. The morphology of HBECs and HLFs cultured alone or co-cultured with or without $\mathrm{O}_{3}$ stimulation was determined (Fig. 1). Results indicated the cells in culture demonstrated a normal shape and size individually (HBECs 
were cuboidal-like shape and HLFs were spindle-like shape) and were organized in usual structures collectively (HBECs were in a relatively uniform monolayer and HLFs were in a hill-valley-like formation), respectively. When the proliferation of HBECs was evaluated using the MTT method, the OD values were not significantly different between $\mathrm{O}_{3}$-stimulated HBECs and their non-stimulated counterparts when cultured for up to $24 \mathrm{~h}$ ( $\mathrm{P}>0.05$; Fig. 2). These results indicated that $\mathrm{O}_{3}$ stimulation had no marked effect on cell morphology regardless of the cell type and culture approach; furthermore, there was no significant effect on the cell proliferation of HBECs.

Co-culture with $\mathrm{O}_{3}$-stimulated $\mathrm{HBECS}$ enhances cell proliferation of $H L F s$. To investigate the cell proliferation of Fibro, Co-culture and $\mathrm{O}_{3}$ co-culture groups, the MTT assay was performed (Fig. 3). In comparison with the Fibro group, proliferation was significantly decreased in the Co-culture group $(0.252 \pm 0.018$ vs. $0.241 \pm 0.017$, respectively; $\mathrm{P}<0.05)$, which indicated that co-culture conditions without $\mathrm{O}_{3}$ stimulation inhibited the proliferation of HLFs. However, cell proliferation of the $\mathrm{O}_{3}$ co-culture group was significantly increased compared with the Fibro group $(0.263 \pm 0.017$ vs. $0.252 \pm 0.018$, respectively; $\mathrm{P}<0.05)$ and Co-culture group $(0.263 \pm 0.017$ vs. $0.241 \pm 0.017$, respectively; $\mathrm{P}<0.01)$, respectively. These findings suggested that co-culture with $\mathrm{O}_{3}$-stimulated HBECs significantly enhanced the proliferation of HLFs when compared with HLFs cultured alone. Furthermore, co-culture with $\mathrm{O}_{3}$-stimulated HBECs significantly reversed the inhibition of HLF proliferation when co-cultured with HBECs that were not stimulated with $\mathrm{O}_{3}$.

Co-culture with $\mathrm{O}_{3}$-stimulated $\mathrm{HBECs}$ enhances collagen synthesis of HLFs. As indicated in Fig. 4, the effects on collagen synthesis of HLFs co-cultured with $\mathrm{O}_{3}$-stimulated HBECs were similar to those indicated for cell proliferation. Notably, the Co-culture group exhibited significantly decreased collagen synthesis-associated hydroxyproline levels compared with the Fibro group ( $2.014 \pm 0.366$ vs. $2.634 \pm 0.310$, respectively; $\mathrm{P}<0.05$ ), which indicated that co-culture conditions without $\mathrm{O}_{3}$ stimulation reduced the collagen synthesis capacity of HLFs. However, the levels of hydroxyproline from the $\mathrm{O}_{3}$ co-culture group were significantly increased compared with the Co-culture group $(2.919 \pm 0.407$ vs. $2.014 \pm 0.366$, respectively; $\mathrm{P}<0.05)$. These results also suggested that co-culture with $\mathrm{O}_{3}$-stimulated HBECs may reverse the inhibition of HLF collagen synthesis due to co-culture with HBECs that were not stimulated with $\mathrm{O}_{3}$.

Co-culture with $\mathrm{O}_{3}$-stimulated $\mathrm{HBECs}$ influences cytokine secretion in the supernatant of the co-culture system. The concentration of major cytokines, including TGF- $\beta 1$, TNF- $\alpha$ and PGE2, in the supernatant of the co-culture system with $\mathrm{O}_{3}$-stimulated HBECs were assessed (Fig. 5). Results indicated that the concentration of TGF- $\beta 1$ remained high and continuously increased over the $24 \mathrm{~h}$ after co-culture. TNF- $\alpha$ concentration remained low and did not significantly vary over the 24 -h time period. Unlike TGF- $\beta 1$, the concentration of PGE2 was significantly increased to the maximum at $12 \mathrm{~h}$ compared with $6 \mathrm{~h}(\mathrm{P}<0.01)$ and plateaued thereafter. PGE2 concentration was significantly increased at 18 and $24 \mathrm{~h}$ compared with

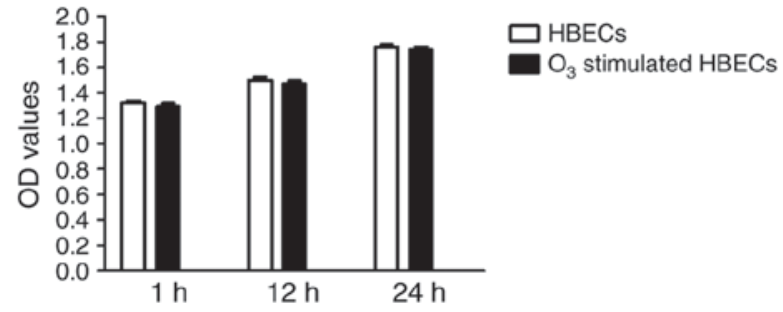

Figure 2. Effect of $\mathrm{O}_{3}$ stimulation on the proliferation of HBECs cultured alone. The proliferation of HBECs was evaluated using the MTT method. The white bars represent HBECs cultured alone without $\mathrm{O}_{3}$ stimulation (control) and the solid bars represent HBECs cultured alone with $\mathrm{O}_{3}$ stimulation, respectively. Data are presented as the mean \pm standard deviation $(n=4)$. HBECs, human bronchial epithelial cells; $\mathrm{O}_{3}$, ozone; OD, optical density.

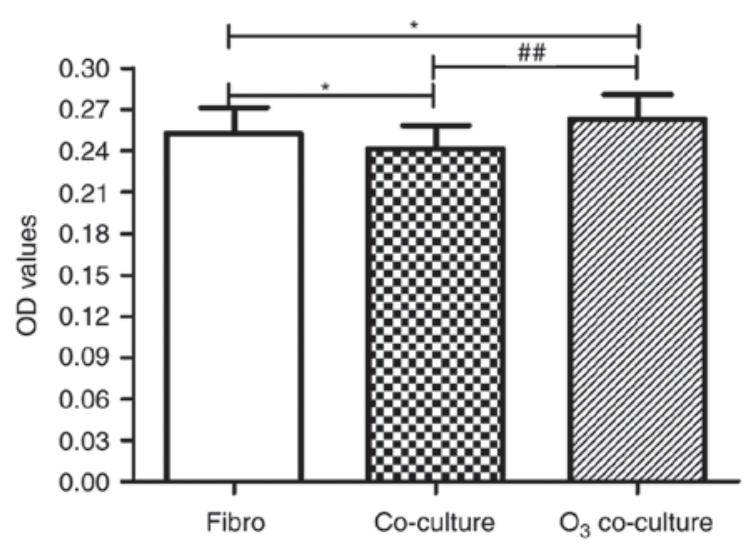

Figure 3. Effect of $\mathrm{O}_{3}$-stressed HBECs on HLF proliferation. HLF proliferation was assessed using the MTT method. Compared with the Fibro group, the proliferation of Co-culture group was significantly inhibited. However, in the $\mathrm{O}_{3}$ co-culture group, the proliferation was significantly increased compared with the Fibro group and Co-culture group. Data are presented as the mean \pm standard deviation $(\mathrm{n}=18)$. ${ }^{*} \mathrm{P}<0.05,{ }^{\# \#} \mathrm{P}<0.01$ as indicated. HBECs, human bronchial epithelial cells; HLFs, human lung fibroblasts; $\mathrm{O}_{3}$, ozone; OD, optical density; Fibro group, HLFs cultured alone; Co-culture group, HLFs co-cultured with $\mathrm{HBECs}$ without $\mathrm{O}_{3}$-stimulation; $\mathrm{O}_{3}$ co-culture group, $\mathrm{HLFs}$ were co-cultured with $\mathrm{O}_{3}$-stimulated HBECs.

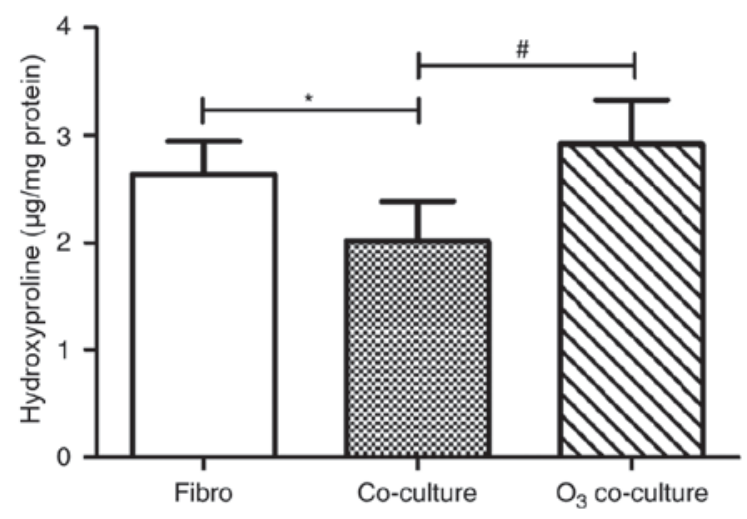

Figure 4. Effect of $\mathrm{O}_{3}$-stressed HBECs on HLF collagen synthesis. HLF collagen synthesis was measured according to the levels of hydroxyproline. Compared with the Fibro group, the hydroxyproline levels in the Co-culture group were significantly inhibited. However, in the $\mathrm{O}_{3}$ co-culture group the hydroxyproline levels were significantly increased compared with the Co-culture group. Data are presented as the mean \pm standard deviation $(n=4)$. ${ }^{*} \mathrm{P}<0.05,{ }^{\#} \mathrm{P}<0.05$ as indicated. HBECs, human bronchial epithelial cells; HLFs, human lung fibroblasts; $\mathrm{O}_{3}$, ozone; Fibro group, HLFs cultured alone; Co-culture group, HLFs co-cultured with $\mathrm{HBEC}$ s without $\mathrm{O}_{3}$-stimulation; $\mathrm{O}_{3}$ co-culture group, HLFs were co-cultured with $\mathrm{O}_{3}$-stimulated HBECs. 


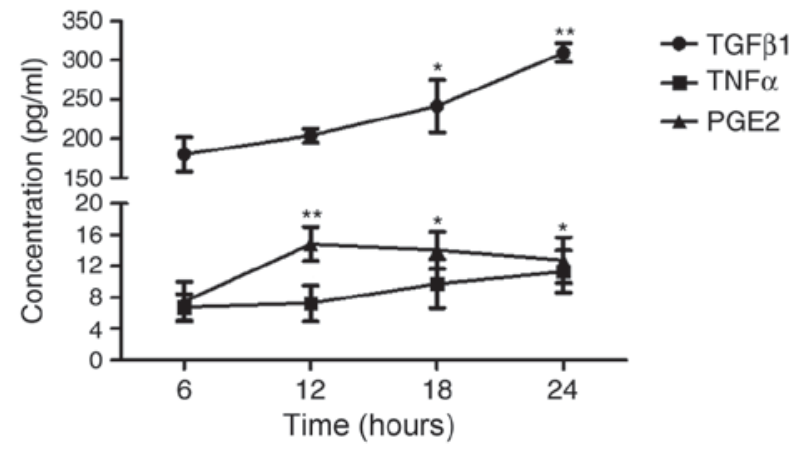

Figure 5. Time course of TGF- $\beta 1$, TNF- $\alpha$ and PGE2 cytokine secretion in the supernatant of the co-culture system after human bronchial epithelial cells were stimulated ozone. TGF- $\beta 1$ and TNF- $\alpha$ secretion was measured using ELISA and PGE2 secretion was measured using a radioimmunoassay. The levels of TGF- $\beta 1$ remained high and continued to gradually increase for up to $24 \mathrm{~h}$. TNF- $\alpha$ levels were relatively low and did not vary significantly over the $24 \mathrm{~h}$. However, the secretion of PGE2 increased significantly between 6 and $12 \mathrm{~h}$ and thereafter plateaued until $24 \mathrm{~h}$. Data are presented as the mean \pm standard deviation $(\mathrm{n}=4) .{ }^{* *} \mathrm{P}<0.01,{ }^{*} \mathrm{P}<0.05$ vs. $6 \mathrm{~h}$. TGF- $\beta 1$, transforming growth factor- $\beta 1$; TNF- $\alpha$, tumor necrosis factor- $\alpha$; PGE2, prostaglandin E2.

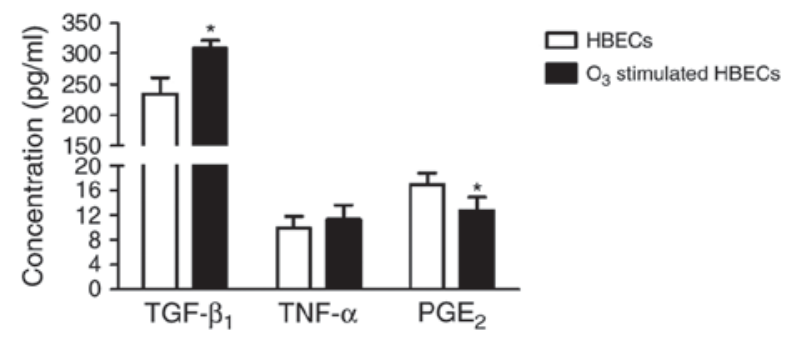

Figure 6. Effect of $\mathrm{O}_{3}$ stimulation on the concentration of TGF- $\beta 1$, TNF- $\alpha$ and PGE2 cytokines in HBECs cultured alone. The concentration levels of the cytokines TGF- $\beta 1$ and TNF- $\alpha$ were measured using ELISA, and PGE2 was measured using a radioimmunoassay. The white bars represent HBECs cultured alone without $\mathrm{O}_{3}$-stimulation (control) and the filled bars represent HBECs cultured alone with $\mathrm{O}_{3}$-stimulation, respectively. Data are presented as the mean \pm standard deviation $(n=4) .{ }^{*} \mathrm{P}<0.05$ vs. HBECS. TGF- $\beta 1$, transforming growth factor- $\beta 1$; TNF- $\alpha$, tumor necrosis factor- $\alpha$; PGE2, prostaglandin $\mathrm{E} 2 ; \mathrm{O}_{3}$, ozone.

$6 \mathrm{~h}(\mathrm{P}<0.05)$, but no significant difference was identified when compared with $12 \mathrm{~h}$.

When compared with HBECs alone, the $\mathrm{O}_{3}$-stimulated HBECs cultured for $24 \mathrm{~h}$ exhibited significantly increased TGF- $\beta 1$ concentration $(234.80 \pm 25.55$ vs. $309.47 \pm 12.22 \mathrm{pg} / \mathrm{ml}$, respectively; $\mathrm{P}<0.05$; Fig. 6). However, the concentration of PGE2 was significantly decreased in $\mathrm{O}_{3}$-stimulated $\mathrm{HBECs}$ compared with HBECs alone (12.74 \pm 2.19 vs. $16.97 \pm 1.92 \mathrm{pg} / \mathrm{ml}$, respectively; $\mathrm{P}<0.05)$ and no significant difference was indicated in the concentration of TNF- $\alpha$ between the experimental groups $(\mathrm{P}>0.05)$.

Correlation between cytokine secretion and cell proliferation and collagen synthesis in HLFs. In order to investigate whether cell proliferation or collagen synthesis was associated with the secretion of cytokines when HLFs were co-cultured with $\mathrm{O}_{3}$-stimulated HBECs, correlation analysis between HLF proliferation and hydroxyproline levels and cytokine secretion was performed (Fig. 7). Results indicated a significant positive correlation between the secretion of TGF- $\beta 1$ from the co-cultured system with $\mathrm{O}_{3}$-stimulated HBECs and cell proliferation $(\mathrm{r}=0.772, \mathrm{P}=0.015)$ and collagen synthesis $(r=0.758, P=0.018$, Fig. 7A and B). Notably, no correlation was indicated between the cytokine secretion of TNF- $\alpha$ with cell proliferation or collagen synthesis of HLFs when co-cultured with $\mathrm{O}_{3}$-stimulated HBECs (Fig. 7C and D). However, a significant negative correlation was indicated between the cytokine secretion of PGE2 and cell proliferation $(r=-0.783$, $\mathrm{P}=0.013)$ and collagen synthesis $(\mathrm{r}=-0.817, \mathrm{P}=0.007)$ of HLFs co-cultured with $\mathrm{O}_{3}$-stimulated HBECs.

Effect of $\mathrm{O}_{3}$ stimulation on TGF- $\beta 1$ expression in HBECs. Immunocytochemistry was conducted to investigate TGF- $\beta 1$ expression levels in HBECs and quantitative expression analysis was performed (Fig. 8). Results indicated that the expression level of TGF- $\beta 1$ in $\mathrm{O}_{3}$-stimulated HBECs cultured for $24 \mathrm{~h}$ was increased compared with HBECs alone (Fig. 8A). This difference was statistically significant $(\mathrm{P}<0.05$; Fig. $8 \mathrm{~B})$. In the co-culture system of HBECs and HLFs, the expression level of TGF- $\beta 1$ was similarly enhanced in the presence of $\mathrm{O}_{3}$-stimulated HBECs (data not shown).

\section{Discussion}

Damage to the bronchial epithelium destroys the integrity of airway structure and function, leading to instability of the local microenvironment and dysfunction of the airways. These are initiative events of multiple airway diseases, including asthma and bronchitis (23). Repeated airway injury and abnormal repair may cause chronic airway inflammation, which eventually results in airway remodeling, as characterized by the activation and proliferation of fibroblasts and accumulation of the ECM (24). As one of the major structural cells of the airway submucosa, lung fibroblasts are known to contribute to the formation of subepithelial fibrosis, increase airway responsiveness and promote airway remodeling (25-27). Furthermore, lung fibroblasts have been acknowledged as the primary cells that produce ECM proteins to form collagen fibers, elastic fibers and reticular fibers, which are downstream components of the airway remodeling process (28). Although the function of lung fibroblasts has been extensively studied, it is not clear whether stress induced on the bronchial epithelium from the external environment, including air pollutants, may influence the submucosal lung fibroblasts to contribute to pathological airway remodeling. A useful model to explore this effect is the use of $\mathrm{O}_{3}$ to stimulate the bronchial epithelium prior to examination of the cellular functions of adjacent fibroblasts not in direct contact of $\mathrm{O}_{3}(29) . \mathrm{O}_{3}$ is a common major component of air pollution and has been revealed in various studies to cause airway epithelial shedding, airway inflammation and airway hyperresponsiveness $(16,30)$. Therefore, the aim of the present study was to co-culture HLFs with airway epithelial cells pre-stimulated with $\mathrm{O}_{3}$ and subsequently measure the functional changes, including collagen synthesis, of the fibroblasts. Results of the present study indicated that, although $\mathrm{O}_{3}$ stimulation seemed to cause no noticeable changes in cell morphology or proliferation of HBECs cultured for up to $24 \mathrm{~h}$, functional changes in the co-culture system of $\mathrm{O}_{3}$-stimulated HBECs and HLFs were indicated. Specifically, in the co-culture group without $\mathrm{O}_{3}$ stimulation, the proliferation of HLFs was significantly 
A

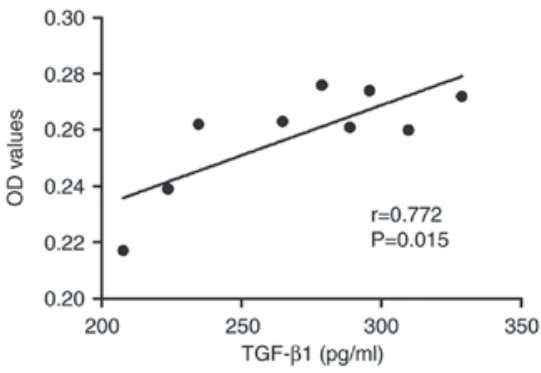

C

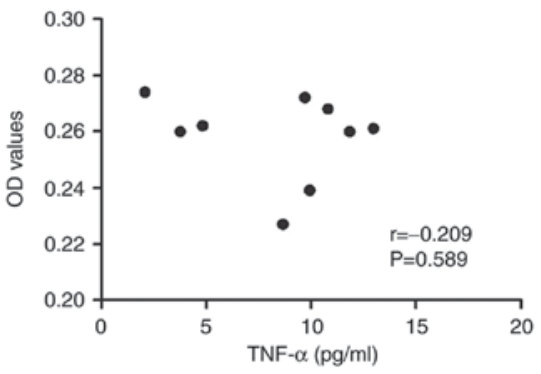

$\mathrm{E}$

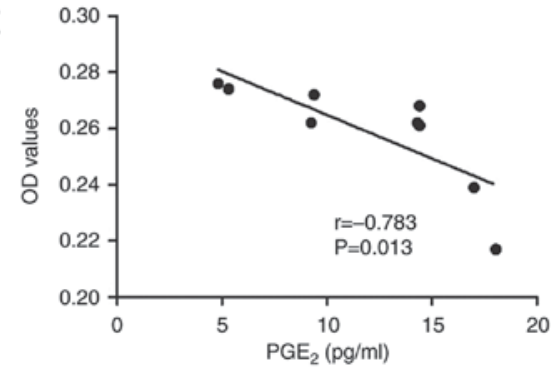

$\mathrm{B}$
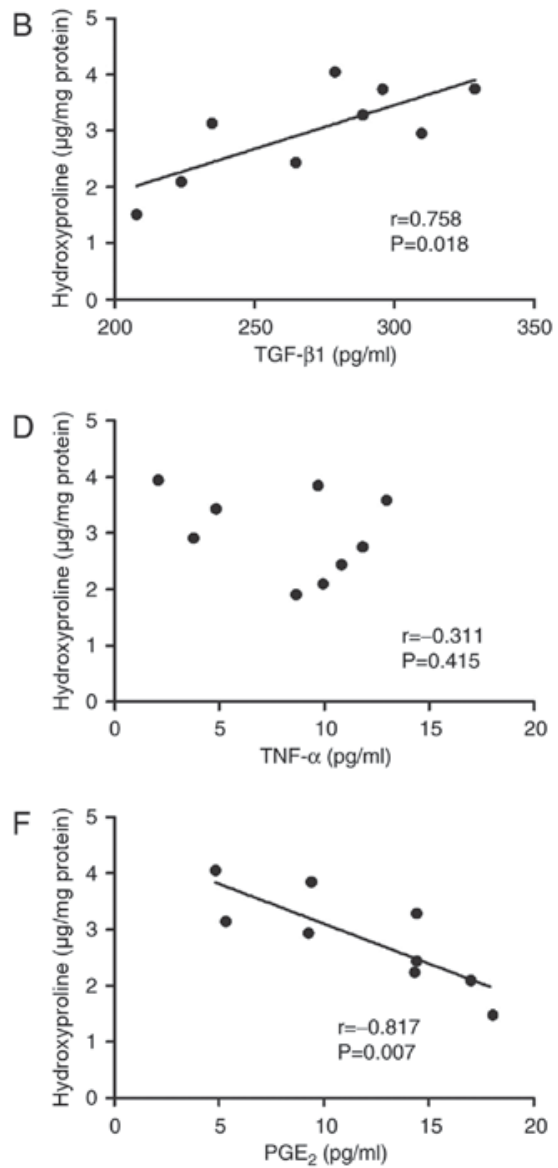

Figure 7. Correlation between cytokine concentration and cell proliferation and collagen synthesis in $\mathrm{HLFs}_{\mathrm{s}}$ co-cultured with $\mathrm{O}_{3}$-stressed HBECs (A and B) A positive linear correlation between proliferation of HLFs and the concentration of TGF- $\beta 1$ in the co-culture supernatant. Collagen synthesis capacity in the culture supernatant was also positively correlated with TGF- $\beta 1$ concentration $(\mathrm{r}=0.758, \mathrm{P}=0.018)$. $(\mathrm{C}$ and $\mathrm{D})$ There was no correlation between the proliferation and TNF- $\alpha$ concentration $(r=0.209, \mathrm{P}=0.589)$, nor between collagen synthesis and TNF- $\alpha$ concentration $(\mathrm{r}=0.311$, $\mathrm{P}=0.415)$. $(\mathrm{E}$ and $\mathrm{F}) \mathrm{A}$ negative linear correlation between the proliferation and PGE2 concentration of HLFs $(\mathrm{r}=0.783, \mathrm{P}=0.013)$ and between collagen synthesis and PGE2 concentration ( $r=0.817, \mathrm{P}=0.007$ ) was indicated. TGF- $\beta 1$, transforming growth factor- $\beta 1$; TNF- $\alpha$, tumor necrosis factor- $\alpha$; PGE2, prostaglandin E2; $\mathrm{O}_{3}$, ozone; HBECs, human bronchial epithelial cells; HLFs, human lung fibroblasts; OD, optical density.

inhibited. However, co-culture of $\mathrm{HLFs}_{\text {with }} \mathrm{O}_{3}$-stressed $\mathrm{HBECs}$ resulted in significantly enhanced HLF proliferation, indicating that $\mathrm{O}_{3}$ stimulation reversed co-culture-induced inhibition of cell proliferation. $\mathrm{O}_{3}$ stimulation on HBECs had a similar effect on the collagen synthesis capacity of the HLFs in the in vitro co-culture model. These results suggest that $\mathrm{O}_{3}$ stress on the airway epithelium may be associated with the pathogenesis of airway remodeling via its indirect effect on the submucosal structural cells, including the HLFs.

The bronchial epithelium is an important source of complex inflammatory mediators, including cytokines and chemokines (31). By secreting inflammatory mediators, HBECs may interact with interstitial fibroblasts and mediate the process of epithelial-mesenchymal transition or fibroblast-myofibroblast transition, therefore actively participating in asthmatic airway remodeling (32-34). In the present study, $\mathrm{O}_{3}$ exposure upregulated the concentration of TGF- $\beta 1$ in the supernatant of the co-culture system persistently for up to $24 \mathrm{~h}$. Furthermore, $\mathrm{O}_{3}$ stress also promoted TGF- $\beta 1$ secretion in the HBEC supernatant and TGF- $\beta 1$ expression in HBECs labeled by immunocytochemistry. In addition, correlation analysis suggested that $\mathrm{O}_{3}$-induced upregulation of TGF- $\beta 1$ secretion was positively and linearly correlated with cell proliferation and collagen synthesis of HLFs co-cultured with $\mathrm{O}_{3}$-stimulated HBECs. These results indicated that the increased TGF- $\beta 1$ content may serve a key role in the proliferation and collagen synthesis of HLFs in the co-culture system. Furthermore, it is acknowledged that TGF- $\beta 1$ may promote differentiation of fibroblasts into myofibroblasts, which secrete collagen and growth factors, including endothelin 1 and vascular endothelial growth factor, and then further promote proliferation of smooth muscle cells and vascular endothelial cells $(35,36)$. Notably, it has also been reported that TGF- $\beta 1$ induces mesenchymal transition of bronchial epithelial cells and thus promotes airway remodeling in asthma (37). Additionally, damaged epithelial cells may extend and amplify remodeling signals into a deeper layer of the mucous membrane (38). Such communication between epithelial cells and mesenchymal cells during asthma has been termed as epithelial mesenchymal trophic unit reactivation (38).

The present study indicated a low concentration of TNF- $\alpha$ was identified in the supernatant of the co-culture system with or without $\mathrm{O}_{3}$ stimulation. TNF- $\alpha$ content was also not significantly correlated with HLF proliferation and collagen synthesis. However, the present study demonstrated that the synthesis of PGE2 in the co-culture system with $\mathrm{O}_{3}$-stressed HBECs was significantly increased during the early stage and plateaued 


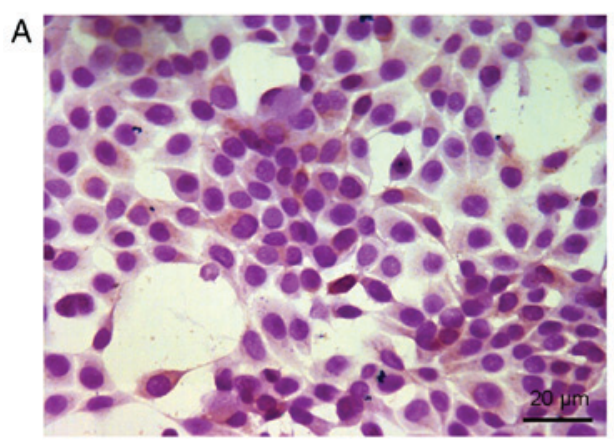

HBECS

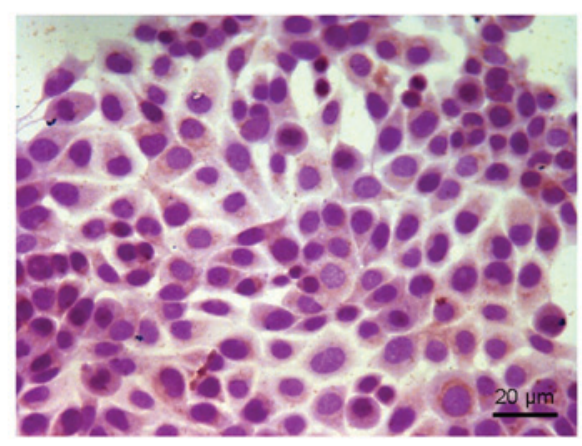

$\mathrm{O}_{3}$ stimulated HBECS

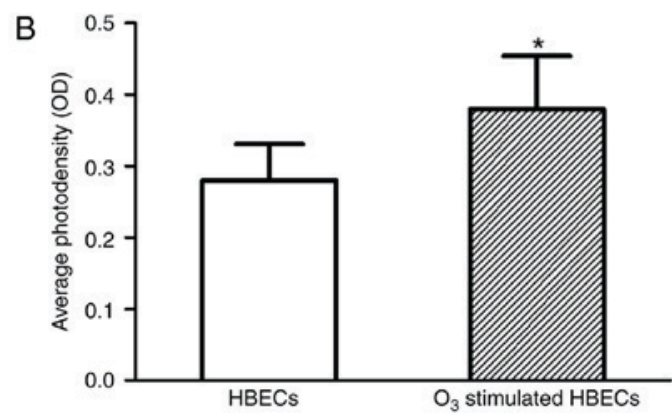

Figure 8. Representative images and corresponding quantitative expression level of TGF- $\beta 1$ in HBECs with or without $\mathrm{O}_{3}$ stimulation. HBECs were cultured alone without $\mathrm{O}_{3}$ stimulation (control) or cultured alone with $\mathrm{O}_{3}$ stimulation. (A) TGF- $\beta 1$ in HBECs was labeled by immunocytochemistry and imaged by photomicroscope. (B) Expression level of TGF- $\beta 1$ in HBECs was quantified according to the averaged photodensity of the images. Data are presented as the mean \pm standard deviation $(n=4)$. ${ }^{*}<0.05$ vs. HBECs. HBECs, human bronchial epithelial cells; HLFs, human lung fibroblasts; $\mathrm{O}_{3}$, ozone; TGF- $\beta 1$, transforming growth factor- $\beta 1$.

from 12-24 h. However, the secretion of PGE2 in $\mathrm{O}_{3}$-stimulated HBECs was significantly reduced compared with HBECs alone. In addition, correlation analysis indicated a negative linear correlation of PGE2 content with HLF proliferation and collagen synthesis. Therefore, the present findings suggested the regulatory effect of $\mathrm{O}_{3}$-stressed HBECs on HLF activity was associated with reduced PGE2 content in the airway tissues. Notably, PGE2 is a lipid mediator that may be derived from cell membrane phospholipids via the cyclooxygenase signaling pathway of arachidonic acid metabolism (39). PGE2 released from HBECs has been reported to relax airway smooth muscles, reduce the sensitivity of smooth muscles to contractile medium, inhibit the proliferation of smooth muscle cells and fibroblast activity and enhance the tolerance of lung epithelial cells to injury factors (23). These findings suggest that PGE2 may act as a negative feedback factor to counteract $\mathrm{O}_{3}$-induced proliferation and airway remodeling processes.

In the present study, the fact that the HBECs without $\mathrm{O}_{3}$ stimulation in the co-culture system inhibited the proliferation of HLFs is conducive to maintaining the normal structure and function of the bronchial airways. However, co-culture with $\mathrm{O}_{3}$-stimulated HBECs with HLFs resulted in increased cell proliferation and collagen synthesis of the HLFs and increased secretion of TGF- $\beta 1$. Considering the pro- and anti-inflammatory properties of TGF- $\beta 1$ and PGE2 respectively, the present findings suggest that the possible mechanism involved in the effect of $\mathrm{O}_{3}$ stimulation on the co-culture system may lie in the system's ability to maintain balance between pro- and anti-inflammatory factors. Under physiological conditions, the expression of anti-inflammatory factors, including PGE2, may prevail in the system to inhibit the proliferation and collagen synthesis of fibroblasts via PGE2 receptor EP2 subtype binding and cAMP production, therefore maintaining the airway homeostasis $(40,41)$. However, under a stressed state, such as with $\mathrm{O}_{3}$ stimulation, the expression of pro-inflammatory factors, including TGF- $\beta 1$, may be increased in the system and result in enhanced cell proliferation and collagen synthesis of fibroblasts, which may primarily occur through the regulation of p21/Waf1 gene transcription factors and the cyclin E-associated kinase (42). This may ultimately result to chronic and permanent airway remodeling in vivo.

In conclusion, the present findings suggest that $\mathrm{O}_{3}$ stimulation of HBECs is a likely factor in promoting cell proliferation and collagen synthesis activity of HLFs via the regulation of pro- and/or anti-inflammatory cytokines, including TGF- $\beta 1$ and PGE2. Such cellular and molecular functional associations between HBECs and HLFs in response to $\mathrm{O}_{3}$ stimulation may provide an important connection between air pollution and airway remodeling in diseases such as asthma.

\section{Acknowledgements}

The authors would like to thank Professor Xiaoqun Qin of Central South University (Changsha, China) for his valuable advice to the data analysis and manuscript drafting.

\section{Funding}

The present study was supported by the National Natural Science Foundation of China (grant no. 11532003). 


\section{Availability of data and materials}

All data generated or analyzed during this study are included in this published article.

\section{Authors' contributions}

YW, HO and LD designed the study. YW and MT performed the experiments. YW, HO and LD wrote the manuscript.

\section{Ethics approval and consent to participate}

All experiments using in vitro cultured human bronchial epithelial cells and lung fibroblasts were approved by the Medical Ethics Committee of Changzhou University (Changzhou, China) according to Ethics Examination Methods on Human Related Biomedical Research issued by China's Health Ministry (approval ref. no. CCZUBME20150516YW).

\section{Consent for publication}

Not applicable.

\section{Competing interests}

The authors declare that they have no competing interests.

\section{References}

1. Busse WW: Inflammation in asthma: The cornerstone of the disease and target of therapy. J Allergy Clin Immunol 102: S17-S22, 1998.

2. Boulet LP: Airway remodeling in asthma: Update on mechanisms and therapeutic approaches. Curr Opin Pulm Med 24: 56-62, 2018.

3. Dekkers BG, Maarsingh H, Meurs H and Gosens R: Airway structural components drive airway smooth muscle remodeling in asthma. Proc Am Thorac Soc 6: 683-692, 2009.

4. Burgess JK, Ceresa C, Johnson SR, Kanabar V, Moir LM Nguyen TT, Oliver BG, Schuliga M and Ward J: Tissue and matrix influences on airway smooth muscle function. Pulm Pharmacol Ther 22: 379-387, 2009.

5. Vogel ER, Britt RD Jr, Faksh A, Kuipers I, Pandya H, Prakash YS, Martin RJ and Pabelick CM: Moderate hyperoxia induces extracellular matrix remodeling by human fetal airway smooth muscle cells. Pediatr Res 81: 376-383, 2017.

6. To T, Stanojevic S, Moores G, Gershon AS, Bateman ED, Cruz AA and Boulet LP: Global asthma prevalence in adults: Findings from the cross-sectional world health survey. BMC Public Health 12: 204, 2012.

7. Turner MC, Jerrett M, Pope CA III, Krewski D, Gapstur SM, Diver WR, Beckerman BS, Marshall JD, Su J, Crouse DL and Burnett RT: Long-term ozone exposure and mortality in a large prospective study. Am J Respir Crit Care Med 193: 1134-1142, 2016.

8. Berman JD, Fann N, Hollingsworth JW, Pinkerton KE, Rom WN, Szema AM, Breysse PN, White RH and Curriero FC: Health benefits from large-scale ozone reduction in the United States. Environ Health Perspect 120: 1404-1410, 2012.

9. Miller DB, Snow SJ, Henriquez A, Schladweiler MC, Ledbetter AD, Richards JE, Andrews DL and Kodavanti UP: Systemic metabolic derangement, pulmonary effects, and insulin insufficiency following subchronicozone exposure in rats. Toxicol Appl Pharmacol 306: 47-57, 2016.

10. Avdalovic MV, Tyler NK, Putney L, Nishio SJ, Quesenberry S, Singh PJ, Miller LA, Schelegle ES, Plopper CG, Vu T and Hyde DM: Ozone exposure during the early postnatal period alters the timing and pattern of alveolar growth and development in nonhuman primates. Anat Rec (Hoboken) 295: 1707-1716, 2012.
11. Carey SA, Ballinger CA, Plopper CG, McDonald RJ, Bartolucci AA, Postlethwait EM and Harkema JR: Persistent rhinitis and epithelial remodeling induced by cyclic ozone exposure in the nasal airways of infant monkeys. Am J Physiol Lung Cell Mol Physiol 300: L242-L254, 2011

12. Wiegman $\mathrm{CH}$, Michaeloudes C, Haji G, Narang P, Clarke CJ, Russell KE, Bao W, Pavlidis S, Barnes PJ, Kanerva J, et al: Oxidative stress-induced mitochondrial dysfunction drives inflammation and airway smooth muscle remodeling in patients with chronic obstructive pulmonary disease. J Allergy Clin Immunol 136: 769-780, 2015.

13. Qin XQ, Xiang Y,Luo ZQ, Zhang CQ and Sun XH: Fibronectin or RGD peptide promotes nitric oxide synthesis of rabbit bronchial epithelial cells. Sheng Li Xue Bao 52: 519-521, 2000 (In Chinese).

14. Ren YH, Qin XQ, Guan CX, Luo ZQ, Zhang CQ and Sun XH: Temporal and spatial distribution of VIP, CGRP and their receptors in the development of airway hyperresponsiveness in the lungs. Sheng Li Xue Bao 56: 137-146, 2004.

15. Tan YR, Qi MM, Qin XQ, Xiang Y, Li X, Wang Y, Qu F, Liu HJ and Zhang JS: Wound repair and proliferation of bronchial epithelial cells enhanced by bombesin receptor subtype 3 activation. Peptides 27: 1852-1858, 2006.

16. Leroy P, Tham A, Wong H, Tenney R, Chen C, Stiner R, Balmes JR, Paquet AC and Arjomandi M: Inflammatory and repair pathways induced in human bronchoalveolar lavage cells with ozone inhalation. PLoS One 10: e0127283, 2015.

17. Gruenert DC, Finkbeiner WE and Widdicombe JH: Culture and transformation of human airway epithelial cells. Am J Physiol 268: L347-L360, 1995.

18. Chiariello M,Ambrosio G,Cappelli-Bigazzi M,Perrone-Filardi P, Brigante F and Sifola C: A biochemical method for the quantitation of myocardial scarring after experimental coronary artery occlusion. J Mol Cell Cardiol 18: 283-290, 1986.

19. Woessner JF Jr: The determination of hydroxyproline in tissue and protein samples containing small proportions of this amino acid. Arch Biochem Biophys 93: 440-447, 1961.

20. Laato M, Kähäri VM, Niinikoski J and Vuorio E: Epidermal grow th factor increases collagen production in granulation tissue by stimulation of fibroblast proliferation and not by activation of procollagen genes. Biochem J 247: 385-388, 1987.

21. Rhaleb NE, Peng H, Harding P, Tayeh M, LaPointe MC and Carretero OA: Effect of N-acetyl-seryl-aspartyl-lysyl-pro line on DNA and collagen synthesis in rat cardiac fibroblasts. Hypertension 37: 827-832, 2001.

22. Upreti GC, Wang Y, Finn A, Sharrock A, Feisst N, Davy M and Jordan RB: U-2012: An improved Lowry protein assay, insensitive to sample color, offering reagent stability and enhanced sensitivity. Biotechniques 52: 159-166, 2012.

23. Hirota N and Martin JG: Mechanisms of airway remodeling. Chest 144: 1026-1032, 2013.

24. Fehrenbach H, Wagner C and Wegmann M: Airway remodeling in asthma: What really matters. Cell Tissue Res 367: 551-569, 2017.

25. Roche WR: Fibroblasts and asthma. Clin Exp Allergy 21:545-8. 1991.

26. Sarna M, Wojcik KA, Hermanowicz P, Wnuk D, Burda K, Sanak M, Czyż J and Michalik M: Undifferentiated bronchial fibroblasts derived from asthmatic patients display higher elastic modulus than their non-asthmatic counterparts. PLoS One 10: $\mathrm{e} 0116840,2015$.

27. Ball SL, Mann DA, Wilson JA and Fisher AJ: The role of the fibroblast in inflammatory upper airway conditions. Am J Pathol 186: 225-233, 2016.

28. Al-Muhsen S, Johnson JR and Hamid Q: Remodeling in asthma. J Allergy Clin Immunol 128: 451-462, 2011.

29. Zhang CQ, Tan YR and Qin XQ: Stimulation of ozone stress on the adhesion of inflammatory cells to bronchial epithelial cells. Hunan Yi Ke Da Xue Xue Bao 27: 192-194, 2002 (In Chinese).

30. Lambert JA and Song W: Ozone-induced airway hyperresponsiveness: Roles of ROCK isoforms. Am J Physiol Lung Cell Mol Physiol 309: L1394-L1397, 2015.

31. Polito AJ and Proud D: Epithelia cells as regulators of airway inflammation. J Allergy Clin Immunol 102: 714-718, 1998.

32. Minor DM and Proud D: Role of human rhinovirus in triggering human airway epithelial-mesenchymal transition. Respir Res 18: 110, 2017.

33. Pain M, Bermudez O, Lacoste P, Royer PJ, Botturi K, Tissot A, Brouard S, Eickelberg O and Magnan A: Tissue remodeling in chronic bronchial diseases: From the epithelial to mesenchymal phenotype. Eur Respir Rev 23: 118-130, 2014. 
34. Reeves SR, Kolstad T, Lien TY, Herrington-Shaner S and Debley JS: Fibroblast-myofibroblast transition is differentially regulated by bronchial epithelial cells from asthmatic children. Respir Res 16: 21, 2015.

35. Ojiaku CA, Yoo EJ and Panettieri RA Jr: Transforming growth factor $\beta 1$ function in airway remodeling and hyperresponsiveness. The missing link? J Respir Cell Mol Biol 56: 432-442, 2017.

36. Yang YC, Zhang N, Van Crombruggen K, Hu GH, Hong SL and Bachert C: Transforming growth factor-betal in inflammatory airway disease: A key for understanding inflammation and remodeling. Allergy 67: 1193-1202, 2012.

37. Yang ZC, Yi MJ, Ran N, Wang C, Fu P, Feng XY, Xu L and $\mathrm{Qu} \mathrm{ZH}$ : Transforming growth factor- $\beta 1$ induces bronchial epithelial cells to mesenchymal transition by activating the Snail pathway and promotes airway remodeling in asthma. Mol Med Rep 8: 1663-1668, 2013.

38. Holgate ST, Davies DE, Puddicombe S, Richter A, Lackie P, Lordan J and Howarth P: Mechanisms of airway epithelial damage: Epithelial-mesenchymal interactions in the pathogenesis of asthma. Eur Respir J 22 (Suppl 44): S24-S29, 2003.

39. Wang J, Liu M, Zhang X, Yang G and Chen L: Physiological and pathophysiological implications of PGE2 and the PGE2 synthases in the kidney. Prostaglandins Other Lipid Mediat 134: $1-6,2018$.
40. Huang S, Wettlaufer SH, Hogaboam C, Aronoff DM and Peters-Golden M: Prostaglandin E(2) inhibits collagen expression and proliferation in patient-derived normal lung fibroblasts via E prostanoid 2 receptor and cAMP signaling. Am J Physiol Lung Cell Mol Physiol 292: L405-L413, 2007.

41. Wang Y, Zhang M, Tan Y, Xiang Y, Liu H, Qu F, Qin L and Qin X: BRS-3 activation transforms the effect of human bronchial epithelial cells from PGE2 mediated inhibition to TGF-betal dependent promotion on proliferation and collagen synthesis of lung fibroblasts. Cell Biol Int 31: 1495-1500, 2007.

42. Miyazaki M, Ohashi R, Tsuji T, Mihara K, Gohda E and Namba M: Transforming growth factor-beta 1 stimulates or inhibits cell growth via down- or up-regulation of p21/Waf1. Biochem Biophys Res Commun 246: 873-80, 1998.

This work is licensed under a Creative Commons Attribution-NonCommercial-NoDerivatives 4.0 International (CC BY-NC-ND 4.0) License. 